\title{
Comparison and application of wind retrieval algorithms for small unmanned aerial systems
}

\author{
T. A. Bonin ${ }^{1,2}$, P. B. Chilson ${ }^{1,2}$, B. S. Zielke ${ }^{1,2}$, P. M. Klein ${ }^{1,3}$, and J. R. Leeman ${ }^{1}$ \\ ${ }^{1}$ School of Meteorology, University of Oklahoma, Norman, Oklahoma, USA \\ ${ }^{2}$ Advanced Radar Research Center, University of Oklahoma, Norman, Oklahoma, USA \\ ${ }^{3}$ Center for Analysis and Prediction of Storms, University of Oklahoma, Norman, Oklahoma, USA
}

Correspondence to: T. A. Bonin (tim.bonin@ou.edu)

Received: 8 October 2012 - Published in Geosci. Instrum. Method. Data Syst. Discuss.: 21 December 2012 Revised: 8 May 2013 - Accepted: 18 June 2013 - Published: 5 July 2013

\begin{abstract}
Recently, there has been an increase in use of Unmanned Aerial Systems (UASs) as platforms for conducting fundamental and applied research in the lower atmosphere due to their relatively low cost and ability to collect samples with high spatial and temporal resolution. Concurrent with this development comes the need for accurate instrumentation and measurement methods suitable for small meteorological UASs. Moreover, the instrumentation to be integrated into such platforms must be small and lightweight. Whereas thermodynamic variables can be easily measured using wellaspirated sensors onboard, it is much more challenging to accurately measure the wind with a UAS. Several algorithms have been developed that incorporate GPS observations as a means of estimating the horizontal wind vector, with each algorithm exhibiting its own particular strengths and weaknesses. In the present study, the performance of three such GPS-based wind-retrieval algorithms has been investigated and compared with wind estimates from rawinsonde and sodar observations. Each of the algorithms considered agreed well with the wind measurements from sounding and sodar data. Through the integration of UAS-retrieved profiles of thermodynamic and kinematic parameters, one can investigate the static and dynamic stability of the atmosphere and relate them to the state of the boundary layer across a variety of times and locations, which might be difficult to access using conventional instrumentation.
\end{abstract}

\section{Introduction}

Winds within the planetary boundary layer (PBL) evolve and vary much faster than winds in the rest of the earth's atmosphere. In the morning, the wind speed near the surface increases as the convective boundary layer (CBL) develops and mixes higher momentum air from aloft downward. Conversely, around sunset, the surface wind speed decreases quickly when the boundary layer decouples as a near-surface inversion develops due to radiational cooling (Barthelmie et al., 1996). During the night, in many places such as the Great Plains of the United States, a low-level jet (LLJ) often develops within a few hundred meters above the ground which persists until the morning when the CBL regrows and momentum is again mixed towards the surface (Wexler, 1961; Bonner, 1968; Parish and Oolman, 2010). The strength of the LLJ is often amplified by an ageostrophic component from flow over sloping terrain (Holton, 1967; Shapiro and Fedorovich, 2009). The process of decoupling at night typically results in low wind speeds at the surface with high wind speeds at the top of the stable boundary layer in the LLJ, while mixing during the daytime results in a relatively uniform wind with height with lower wind speeds near the surface due to frictional effects.

The flow within the PBL is important for many different applications. Understanding the wind patterns within the boundary layer is vital for accurate air quality and wind energy forecasts (Endlich et al., 1982; Seaman and Michelson, 2000; Emeis et al., 2007; Kondragunta et al., 2008). Studying these patterns can be difficult and often requires a variety of in situ measurements from instrumented towers, which 
can only monitor the lower portions of the PBL. Radars, lidars, sodars, wind profilers, and other remote sensing tools are used to measure PBL variables continuously without much human intervention, but are expensive to purchase and each instrument has its own limitations in what variables it can measure for particular height ranges. Additionally, thermodynamic variables are difficult to measure accurately with most remote sensing instruments. Hence, unmanned aerial systems (UASs) are unique instruments for conducting boundary-layer research. These platforms are capable of measuring both thermodynamic and flow parameters within the PBL, while minimizing expenses and providing flexibility to the user.

Within the past decade, there has been an increasing number of UASs developed and used for atmospheric sensing (i.e., Holland et al., 2001; Shuqing et al., 2004; Spiess et al., 2007; van den Kroonenberg et al., 2008; Reuder et al., 2009; van den Kroonenberg et al., 2012; Houston et al., 2012). The nature of the research topics investigated by UASs varies as much as the platforms themselves. Larger more robust platforms, such as the Aerosonde, are capable of carrying extensive instrumentation packages and conducting long research missions, such as investigating the eye wall of tropical cyclones (Lin, 2006). Most UASs that have been developed recently are more focused on investigating the PBL. The meteorological mini unmanned aerial vehicle $\left(\mathrm{M}^{2} \mathrm{AV}\right)$, designed by van den Kroonenberg et al. (2008), has a wingspan of $2 \mathrm{~m}$ and is capable of taking thermodynamic as well as highresolution 3-D wind measurements using a 5-hole probe. It has been used primarily to investigate the PBL, such as measuring the temperature structure-function parameter (van den Kroonenberg et al., 2012). However, the 5-hole probe for the $\mathrm{M}^{2} \mathrm{AV}$ is relatively expensive costing $\sim € 6000$ (J. Bange, personal communication, 2009), while the total of other components for a small UAS is $\sim € 800$. Dias et al. (2012) constructed the Aerolemma, which collects thermodynamic data, and utilized it to calculate convective turbulence scales and the entrainment flux. Several low-cost UASs have also been developed recently for PBL research. The Small Unmanned Meteorological Observer (SUMO) utilizes an offthe-shelf airframe into which meteorological sensors can be placed, such as a temperature and humidity sensor and a barometer, for thermodynamic profiling of the PBL (Reuder et al., 2009).

Small UASs can be relatively inexpensive and have the ability to collect samples with high spatial and temporal resolution (Bonin et al., 2013). Flight plans for autonomous vehicles that utilize autopilots can be customized to examine particular meteorological phenomena and can be adapted "on the fly" to account for evolving conditions or to focus on a particular region of interest. For example, a flight trajectory configured for a quick ascent rate could be used to rapidly penetrate the daytime PBL under convective conditions when the PBL is typically well mixed. At night, the PBL is usually statically stable and contains sharp vertical gradients in its structure. Therefore a slower ascent rate might be more appropriate as a means of acquiring better vertical resolution over a shallow layer. Since UASs are being increasingly utilized for meteorological sensing, accurate instrumentation and observation methods must be developed for these platforms.

Recently, the Advanced Radar Research Center (ARRC) at the University of Oklahoma (OU) has developed a small low-cost UAS, the SMARTSonde (Small Multifunction Research and Teaching Sonde), for boundary-layer research (Chilson et al., 2009). The SMARTSonde platform uses an open source autopilot system, Paparazzi, for autonomous flight. The Paparazzi autopilot hardware package comes with a GPS receiver which provides real-time information on the position of the SMARTSonde. The autopilot uses these data along with pitch and roll estimates from infrared thermopiles or an inertial measurement unit (IMU) in a feedback loop to adjust the flight control surfaces accordingly to maintain a preconfigured flight plan (Brisset et al., 2006). The airframe used for the flights in the study is the NexSTAR EP Select, which is an off-the-shelf radio-controlled airplane. It has a wingspan of $1.74 \mathrm{~m}$ and weighs $\sim 3.5 \mathrm{~kg}$. It is powered by a brushless electric motor to avoid potential contamination of the sensors from fuel used to power a gas engine. The typical airspeed of the NexSTAR during scientific missions varies between $15-20 \mathrm{~m} \mathrm{~s}^{-1}$ and flights last up to $25 \mathrm{~min}$. The SMARTSonde package is described more thoroughly by Bonin et al. (2013).

The SMARTSonde is capable of directly measuring pressure, temperature, relative humidity, and trace gas concentrations, such as ozone. An SHT75 is positioned underneath the wing to measure temperature accurately within $0.3 \mathrm{~K}$ and relative humidity within $1.8 \%$. Static pressure is measured within $1.5 \mathrm{~Pa}$ at $1 \mathrm{~Hz}$ by an SCP1000 that is mounted inside the fuselage. Thermodynamic quantities alone have been used to examine the boundary-layer evening transition (Bonin et al., 2013). While thermodynamic variables can be measured during flights from onboard sensors, information about the wind speed and direction is not as easily obtained. Other methods of retrieving the wind information from the UAS flight are necessary.

The three algorithms under investigation in this paper are (i) the best curve fitting method, (ii) no-flow-sensor, and (iii) the Paparazzi autopilot output, as discussed below. These algorithms are used to retrieve the horizontal 2-D wind vector. The first algorithm, best curve fitting, is based loosely on the initial wind retrieval method used by the SUMO group (Reuder et al., 2009), who found the wind speed by dividing the difference between the maximum and minimum ground relative speed by two. However, instead of simply using the maximum and minimum ground speeds around a circle, all GPS derived heading and ground speed measurements from around the circle are used to retrieve the wind profile. The second method is the "no-flow-sensor", detailed by Mayer et al. (2012). This algorithm uses a series of ground speed 
and azimuthal movement to estimate the wind. The third algorithm discussed is integrated into the Paparazzi autopilot system and provides a real-time estimate of the wind speed and direction to the user. These algorithms are based on measurements from an onboard GPS unit. Other ways to measure the wind exist, but require different flight plans than those used by the SMARTSonde or more expensive instruments. For instance, Shuqing et al. (2004) estimated the wind based on the drift of a circular flight path if the aircraft maintains a constant roll rate. The middle of the circle would translate downstream with the wind. More complex sensors for measuring the wind have also been devised (e.g., van den Kroonenberg et al., 2008; Premerlani and Bizard, 2009). The performances of these different algorithms have not been thoroughly compared against each other or with other instrumentation prior to this paper.

While many of the different wind algorithms have been developed for specific platforms, most should work across platforms provided the proper instrumentation. Profiles of the mean horizontal wind can be retrieved using these algorithms. These can be used to complement the thermodynamic variables to calculate boundary-layer stability parameters, such as the Richardson number. Additionally, examining a progressive series of high-resolution wind profiles in the evening could be used to study the development of a LLJ.

\section{Wind retrieval algorithms}

The primary use of the three algorithms is to obtain a vertical profile of the mean horizontal wind. Since all of the methods involve temporal and spatial averaging, they are not useful for determining small fluctuations in the components of the wind over short timescales. However, wind shear in the PBL can be quantified. Each of these methods simply requires instantaneous speed and ground track direction provided by an onboard GPS as input. The retrieval algorithms are based on the fact that the atmospheric wind vector is the sum of the ground speed and airspeed vectors, all of which are defined in the earth's coordinate system. This contrasts to the calculation of the wind from many full-sized aircraft and some small- and mid-sized UAS (e.g., van den Kroonenberg et al., 2008; Martin et al., 2011), which have the payload capacity to carry pressure probes to accurately determine the airflow around the aircraft (e.g., Williams and Marcotte, 2000). With this additional information, the airspeed is measured directly from the pressure probe in reference to the aircraft, so a coordinate transformation of the airspeed is needed to calculate the wind speed.

Since only the information from a GPS is used as input, airspeed is not known and needs to be treated as a constant. Therefore, the throttle is maintained at a certain value and angle of attack needs to be assumed to be roughly constant over the integration time of the wind calculation for airspeed to remain invariable. In the future, a pitot tube could be installed

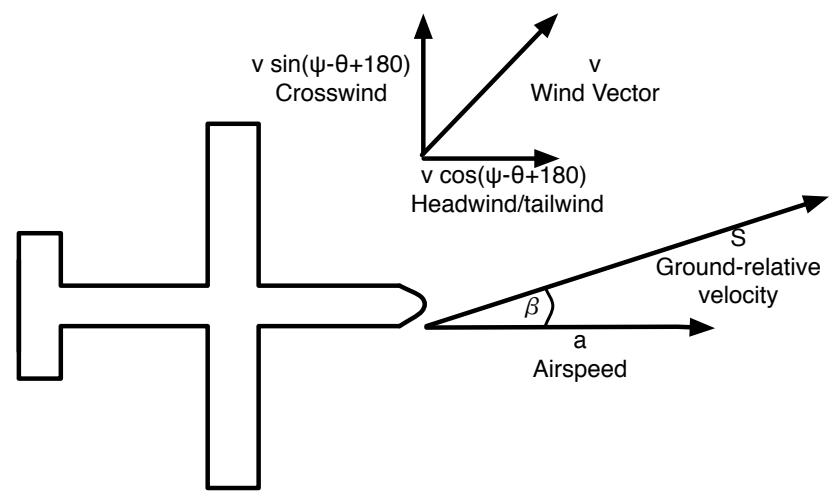

Fig. 1. Diagram showing the components affecting ground-relative movement of the UAS platform used in Eq. (1). The ground-relative velocity is the summation of the airspeed and plane relative wind vectors.

to improve wind speed estimates by having measurements of the true airspeed.

\subsection{Best curve fitting}

One method of retrieving information about the wind from a SMARTSonde flight is by fitting a curve to the UAS's ground relative speed provided by the onboard GPS unit, which is called the best curve fitting method (BCF). This method is similar to the wind algorithm used by Reuder et al. (2009). The magnitude of the ground-relative speed, $S$, can be expressed as

$S^{2}=(a+v \cos (\psi-\theta+180))^{2}+(v \sin (\psi-\theta+180))^{2}$,

where $\psi$ is the airplane heading with north being $0^{\circ}, \theta$ is the wind direction using standard meteorological convention, $a$ is the airspeed of the aircraft, and $v$ is the wind speed. A diagram showing the components of Eq. (1) is provided in Fig. 1. For this method, $a$ can be treated as a constant if the aircraft is flying with a constant throttle and pitch. Although it must be noted that the true airspeed will vary slightly as the angle of attack changes dynamically, a mean airspeed over a circle flown by the UAS exists based on the mean angle of attack.

The values of $S$ and the ground track angle are known since they are recorded every second from the GPS. It is important to note that ground track angle is different from the heading, $\psi$, as the difference between them is the sideslip angle, $\beta$, as shown in Fig. 1. However, it is possible to back out the true heading of the aircraft from the ground track angle, since the ground track vector is the summation of the airspeed and wind vectors. Based on vector math and trigonometry from Fig. 1, $\beta$ can be expressed as

$\beta=\tan ^{-1}\left(\frac{v \sin (\psi-\theta+180)}{v \cos (\psi-\theta+180)+a}\right)$, 


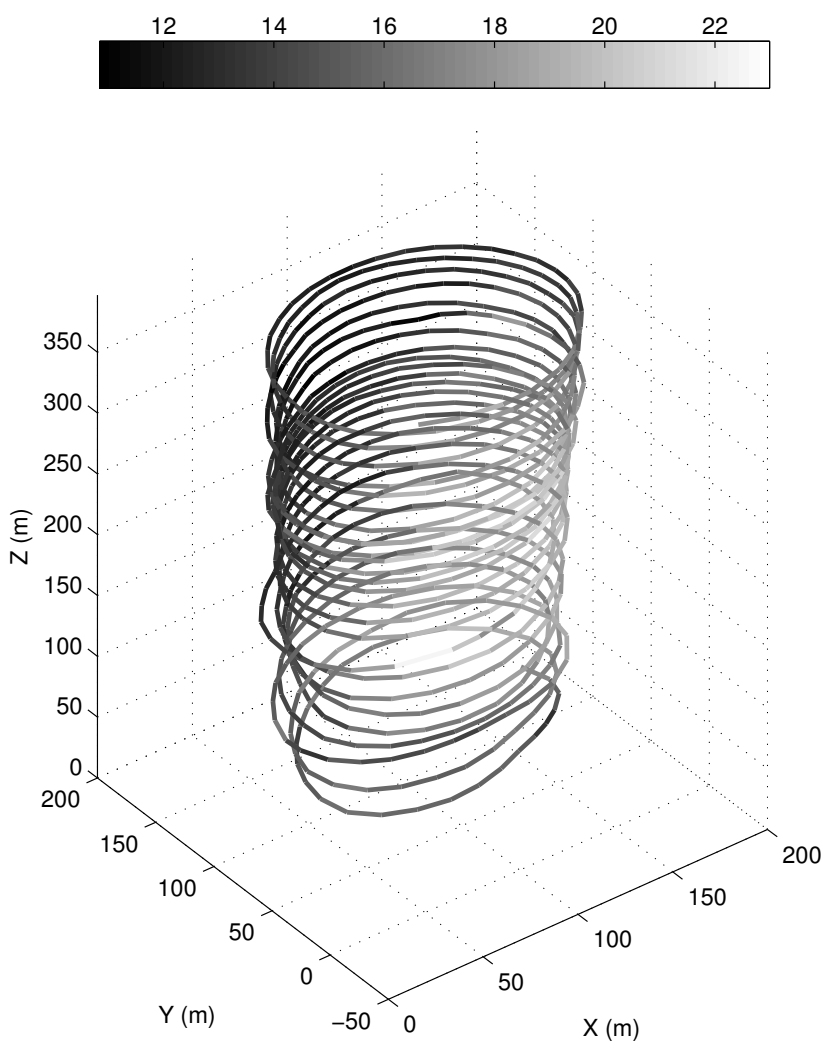

Fig. 2. A trace of a flight path on 17 November 2011. The shading indicates the SMARTSonde's ground relative speed $\left(\mathrm{m} \mathrm{s}^{-1}\right)$. On this day, the wind direction was northerly, becoming more easterly with height. The winds affect on the aircraft's speed can be seen, as the aircraft moved faster with a tailwind and slower with a headwind.

where the numerator is the crosswind and the denominator is the summation of the airspeed and the headwind. $\psi$ is found by taking the difference between the ground track angle and $\beta$. This relationship between the ground track with $\psi$ can be used in the iterative process of determining the horizontal wind through the polynomial curve fitting.

With this information, a polynomial curve fitting can be performed to determine the values of $a, v$, and $\theta$. While the fitting may be done as frequently as desired, it may not provide an accurate estimate of the wind speed and direction if the analyzed dataset is windowed too narrowly. Ideally, the dataset would contain a large number of data points over a wide range of $\psi$. Generally, the fitting is performed each time the aircraft completes a circle, providing the entire range of $\psi$ that is needed for a representative fit of Eq. (1) to the data.

To illustrate the application of the curve fitting method, SMARTSonde data from a helical ascent are depicted in Fig. 2. On this particular day, the prevailing winds were northerly. When the aircraft travels north, the headwind decreases the ground-relative speed. Conversely, the groundrelative speed of the SMARTSonde increases when flying

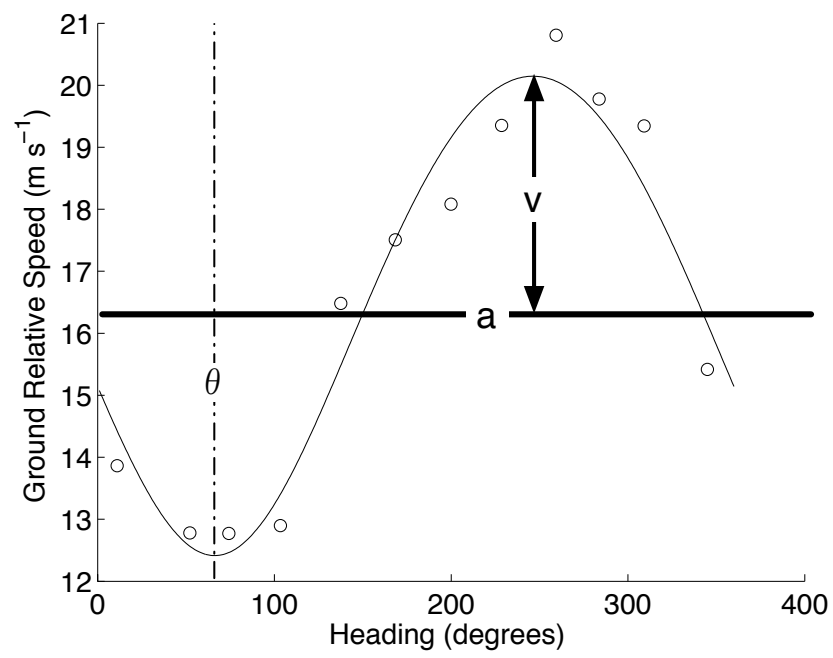

Fig. 3. Example fitting of the equation in the BCF. This corresponds to the circle between 207 and $218 \mathrm{~m}$ a.g.l. The curve indicates the best fit of Eq. (1) and the circles represent the data from the GPS unit. Airspeed $(a)$ is marked by the solid line, wind speed $(v)$ is noted by the arrows, and wind direction $(\theta)$ is shown by the dashdotted line.

southward. Each circle in the flight can be individually examined using the BCF. Equation (1) is fitted to the instantaneous ground-relative velocities. A sample fitting of the data from one particular circle is shown in Fig. 3. By applying this fitting, the wind speed $v$ and wind direction $\theta$ for the average height of the aircraft during the circle is retrieved. This fitting is applied to every circle during the SMARTSonde's ascent so that a wind profile of the PBL can be constructed, as shown in Fig. 4.

The aircraft does not need to fly in a circle to utilize the BCF. The fitting could work with most patterns as long as the airplane changes heading throughout the flight. However, the algorithm is able to provide the most frequent and accurate updates of a wind estimate when a circular flight path is used.

\subsection{No-flow-sensor method}

By using Nelder-Mead optimization (Nelder and Mead, 1965), the wind speed and direction can be retrieved through an alternative method. This method was originally proposed by Mayer et al. (2012) as the "no-flow-sensor". Similar to the $\mathrm{BCF}$, this algorithm utilizes an optimization scheme that relies only on the ground-relative velocity from the GPS unit. The airspeed $a$ is defined as

$a=\frac{1}{n} \sum_{i=1}^{n}\|S(i)-W\|$,

where $n$ is the number of the GPS measurements that are used in the optimization, $S$ consists of the ground-relative velocity vector given by the GPS, and $\boldsymbol{W}$ is the wind vector. All of the quantities are relative to the earth's coordinate 

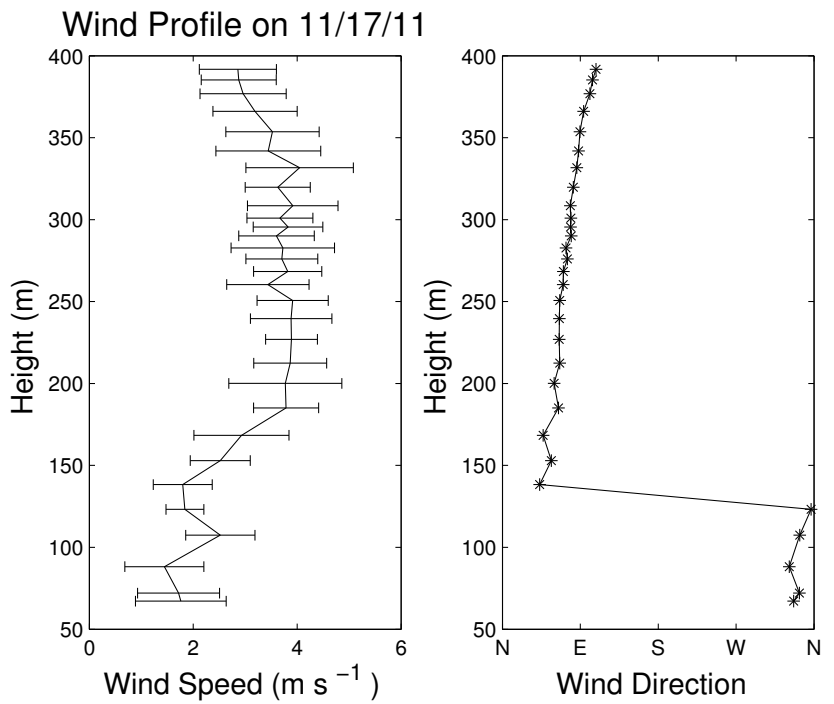

Fig. 4. Derived wind profile by using the BCF on the flight shown in Fig. 2.

system. Assuming perfect measurements and a constant airspeed and wind speed, $\boldsymbol{S}-\boldsymbol{W}-a$ should be equal to zero. Since measurements are not perfect and the true wind fluctuates due to turbulence, $\boldsymbol{S}-\boldsymbol{W}-\boldsymbol{a}$ does not necessarily equal zero; however, since $a$ and $\boldsymbol{S}$ are known values, $\boldsymbol{W}$ can be solved. To accomplish this, a standard deviation quantity, $\sigma$, is defined by

$\sigma=\frac{1}{n} \sum_{i=1}^{n}(\|\boldsymbol{S}(i)-\boldsymbol{W}\|-a)^{2}$,

which is minimized using a Nelder-Mead optimization scheme.

For the wind retrievals in this study, 151 GPS-derived values are used in the optimization scheme. This number of ground-relative velocities is based on experimentation with different sample sizes. Since the GPS measurements are sampled at $5 \mathrm{~Hz}$, this corresponds to around $30 \mathrm{~s}$ of flight time. Using a lower number of points, $n$, the wind data become noisy. With a larger sample size, small changes in the wind vector with height are not resolved. To date, the $u$ and $v$ components of the wind have been reliably calculated for SMARTSonde flights using this method. However, due to the fact that the $w$ component is typically smaller than the noise in the GPS data, the vertical wind has not been resolved using this method.

Utilizing the no-flow-sensor, the wind speed can be estimated whenever the aircraft is maintaining a constant airspeed. The aircraft could be following any flight pattern, along a straight path or with many turns. The frequency of independent estimates of the wind speed is a function of the number of points used in the optimization scheme. This quantity may vary depending on the platform and the accuracy of the GPS receiver.

\subsection{Paparazzi wind algorithm}

The Paparazzi autopilot program used by the SMARTSonde for autonomous flight provides an estimate of the wind speed and direction at the flight level. These values are reported every ten seconds. However, the wind algorithm in use with the autopilot software is not well documented. It uses some form of the no-flow-sensor methodology discussed above, but the number of points, $n$, that are used in the optimization are not reported. Paparazzi provides the only real-time estimate of the wind speed, as the other algorithms are used to process the data after the flights are complete. Typically, the estimate of the wind speed from the Paparazzi are erratic for $\sim 30 \mathrm{~s}$ after the aircraft begins autonomous flight, while the other algorithms worked well during this time interval. A relatively accurate first guess would minimize the computing time and iterations needed to solve for the wind vector.

\section{Algorithm performance and comparison}

\subsection{Comparison with rawinsonde}

The three wind algorithms have been used to derive wind measurements for profiles of the PBL for comparison with a nearby rawinsonde and Mesonet station. The rawinsonde wind profiles used for comparison were from Norman, Oklahoma (OUN). Rawinsonde wind measurements are specified to be accurate to within $1 \mathrm{~m} \mathrm{~s}^{-1}$ for each $u$ and $v$ component. The upper-air station is located less than a kilometer away from where the SMARTSonde flights for this study were conducted. The ground near the rawinsonde site is relatively flat, so terrain effects are minimal. Therefore, the rawinsonde observations are expected to be representative of the SMARTSonde observations. While the times of the radiosonde launches did not exactly match the times of the SMARTSonde profiles, the profiles compared were always within $2 \mathrm{~h}$ of each other.

The Oklahoma Mesonet consists of 110 stations throughout the state that measure air temperature, humidity, barometric pressure, wind speed and direction, rainfall, solar radiation, and soil temperatures (Brock et al., 1995; McPherson et al., 2007). The National Weather Center (NWC) Mesonet was used for additional comparison. The Mesonet station is maintained by the Oklahoma Climatological Survey (OCS); data are archived for public use with one minute resolution. The main advantage of using the NWC Mesonet observation is that the wind data, which is measured at $10 \mathrm{~m}$ a.g.l. (above ground level), at the moment of the SMARTSonde's takeoff can be used for comparison. This shows if the $10 \mathrm{~m}$ wind changes significantly between the rawinsonde observation time and the time of the SMARTSonde flight. Wind speed and direction measurements from the NWC Mesonet station are accurate within $0.3 \mathrm{~m}^{-1}$ and $3^{\circ}$, respectively. 

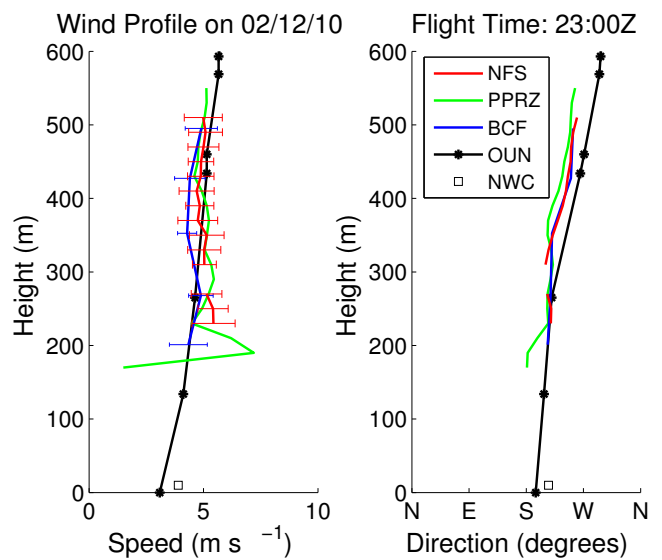

(a)

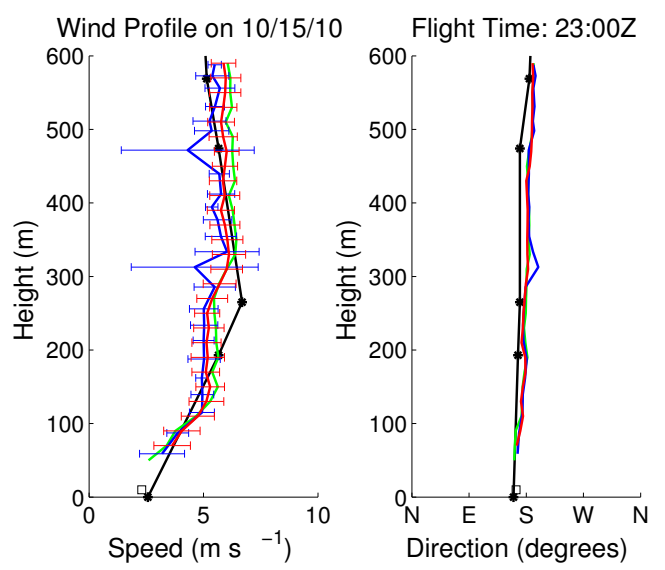

(c)

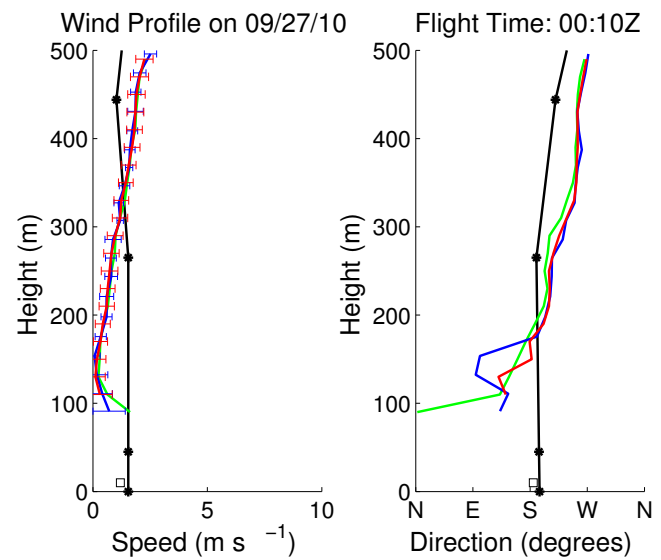

(b)

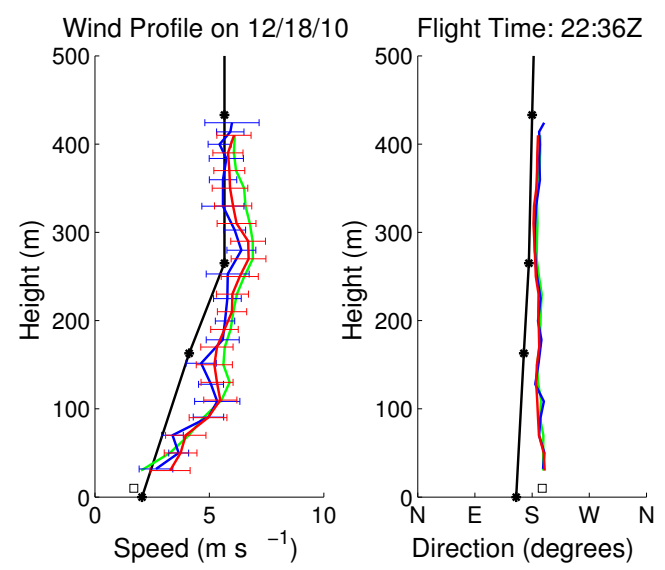

(d)

Fig. 5. Four examples of typical wind profiles using the different algorithms compared against the NWC Mesonet observation at $10 \mathrm{~m}$ (NWC, black square) and the rawinsonde (OUN, solid black line with asterisks). NFS is the no-flow-sensor (red line), PPRZ is the paparazzi output (green line), BCF is the best curve fitting method (blue line).

The great majority of the 60 helical ascent flights conducted for this study occurred during periods when the synoptic-scale forcing was weak, absent of nearby frontal zones that could quickly change the PBL wind profile. Thus, conditions during the balloon launch should be similar to conditions during SMARTSonde flights, provided the two times are within a few hours of each other. Hence, it is reasonable to make direct comparisons between rawinsonde and SMARTSonde observations.

Shown in Fig. 5 are four typical wind profiles calculated using the three methods mentioned above. They are compared with observations from the Norman sounding (OUN) and the NWC Mesonet station. Note that the rawinsonde data are for the official launch time, 00:00 UTC, for all of the cases shown. However, the sondes are usually observed being launched earlier, at 23:00 UTC. Figure 5a depicts an event on 12 February 2010 when there was a noticeable wind direction shift from southerly to westerly between $300-500 \mathrm{~m}$ a.g.l. Based on the $925 \mathrm{mb}$ map and soundings (not shown), this wind shift was associated with an elevated mixed layer moving over the cooler air near the surface. All of the wind data produced using the SMARTSonde's algorithms agreed well with the rawinsonde observation. Another wind shift can also be seen in Fig. 5b. On this day, the winds were much lighter than the previous case, but both the rawinsonde and the wind algorithms still captured the low-level wind shear. In Fig. 5c, a noticeable feature was the weaker winds that were observed below $100 \mathrm{~m}$ a.g.l. This demonstrates that the algorithms are capable of retrieving weaker winds closer to the ground when the SMARTSonde begins a helical ascent at a low altitude. In the final example shown in Fig. 5d, once again weaker winds are observed near the surface. This flight took place $\sim 30 \mathrm{~min}$ prior to the rawinsonde launch. Below $200 \mathrm{~m}$ a.g.l., the SMARTSonde and rawinsonde observations differ in wind direction. However, the SMARTSonde's lowest observation from all three algorithms closely matches the wind direction at the NWC Mesonet at the takeoff time. 
The four example plots comparing algorithm output against the sounding, as well as the many other comparisons not shown here, generally illustrate good agreement between the rawinsonde observations and the different wind algorithms. Differences in wind profiles from the UAS and rawinsonde can be attributed to unreliable rawinsonde data below $300 \mathrm{~m}$ as well as evolution of the PBL wind profile during the evening transition period between rawinsonde and UAS observations. To better determine the accuracy of the algorithms, error statistics were calculated from all of the flights that took place within an hour of a rawinsonde being launched.

Table 1 provides the root mean squared errors (RMSE) between the rawinsonde wind data and UAS retrievals using 22 rawinsonde and UAS profiles. Since rawinsonde wind observations under $300 \mathrm{~m}$ a.g.l. are typically unreliable, data below this height were not used in the computation of error statistics in Table 1. The last column, $|\boldsymbol{V}|$, is the magnitude of the vectorized RMSE for the wind, utilizing the vector addition of the $u$ and $v$ error components. Based on these numbers, both the no-flow-sensor and BCF provide measurements more similar to the rawinsonde than the $\mathrm{Pa}$ parazzi algorithm in nearly every category. While the $\mathrm{BCF}$ has a lower error for the wind speed, the estimate of the wind direction from the no-flow-sensor has a lower RMSE. Both could be used to measure the 2-D wind vector with nearly identical errors. The RMSE for each of the wind components is slightly larger than the error for the rawinsonde system, which is $1 \mathrm{~m} \mathrm{~s}^{-1}$ for $u$ and $v$. This is not surprising considering that the rawinsonde observations have error themselves and the winds may change slightly between the measurement times.

Overall, the three algorithms themselves were in good agreement with each other. No algorithm appeared to perform drastically better than any other when compared against the rawinsonde, but each algorithm has its own advantages. The BCF provides the faster independent updates when the aircraft is flying in a circular pattern compared to the no-flow-sensor. Conversely, the no-flow-sensor method still works well when the aircraft is flying in a straight line, while the BCF does not work well in that condition.

\subsection{Comparison with sodar}

A Scintec XFAS sodar operates on the roof of the NWC and offers yet another wind dataset for comparison. The sodar provides $10 \mathrm{~m}$ vertical resolution estimates of the wind vector averaged over a $15 \mathrm{~min}$ time span. The lowest range gate is $30 \mathrm{~m}$ above the instrument and retrievals can provide data up to $400 \mathrm{~m}$ under ideal conditions, although the typical range is $200 \mathrm{~m}$. The maximum height range varies drastically depending on atmospheric conditions and noise levels of the environment. Wind speed and direction measurements are specified to be accurate within $0.3 \mathrm{~m} \mathrm{~s}^{-1}$ and $1.5^{\circ}$. However, measurement quality is sensitive to the signal-to-noise ratio.
Table 1. Root mean squared errors (RMSE) for algorithms compared to rawinsonde observations for all flights within $1 \mathrm{~h}$ of rawinsonde launch time at heights above $300 \mathrm{~m}$ a.g.l.

\begin{tabular}{lccccc}
\hline Algorithm & $\begin{array}{c}\text { Wind } \\
\text { speed } \\
\left(\mathrm{m} \mathrm{s}^{-1}\right)\end{array}$ & $\begin{array}{c}\text { Wind } \\
\text { direction } \\
\text { (degrees) }\end{array}$ & $\begin{array}{c}\mathrm{u} \text {-comp } \\
\left(\mathrm{m} \mathrm{s}^{-1}\right)\end{array}$ & $\begin{array}{c}\mathrm{v} \text {-comp } \\
\left(\mathrm{m} \mathrm{s}^{-1}\right)\end{array}$ & $\begin{array}{c}|\boldsymbol{V}| \\
\left(\mathrm{m} \mathrm{s}^{-1}\right)\end{array}$ \\
\hline BCF & 1.10 & 15.10 & 1.13 & 1.20 & 1.65 \\
No-flow-sensor & 1.24 & 14.83 & 1.07 & 1.33 & 1.71 \\
Paparazzi & 1.35 & 15.90 & 1.31 & 1.43 & 1.94 \\
\hline
\end{tabular}

Given its continuous data stream and its spatial resolution near the ground, wind measurements from the NWC sodar are well suited for validating wind retrievals from SMARTSonde flights.

A series of flights were conducted on the mornings of 31 October and 17 November 2011 during the morning transition of the boundary layer. The data from several of the flights and the sodar are shown in Fig. 6. On the morning of 31 October, a weak LLJ was observed by the SMARTSonde with a peak wind speed around $150 \mathrm{~m}$ a.g.l. Below this, there was an area of strong wind shear. Although the sodar did not retrieve a wind estimate much above $150 \mathrm{~m}$ a.g.l., the winds below this height agreed very well with those derived from the SMARTSonde flight. Concurrently, there was good agreement between both the sodar and SMARTSonde wind observations during the morning of 17 November. The wind speed increased rapidly with height from 100 to $200 \mathrm{~m}$ a.g.l., as shown with measurements from both instruments. Although there are some differences in the observed wind direction between the two profiles, both tended to show the wind shifting from northerly to more easterly with height. Due to technical problems with the sodar, there have only been limited opportunities for comparisons between the instruments so far; however, observations visually have shown good agreement.

\section{Example application}

\subsection{Calculating the Richardson number}

Since the SMARTSonde is capable of measuring both the wind and thermodynamic variables, it is possible to calculate the gradient Richardson number $(R i)$. The gradient Richardson number is defined as

$R i=\frac{\frac{g}{\theta} \frac{\partial \theta}{\partial z}}{\left(\frac{\partial u}{\partial z}\right)^{2}+\left(\frac{\partial v}{\partial z}\right)^{2}}$,

where $g$ is gravity, $\theta$ is potential temperature, $\frac{\partial \theta}{\partial z}$ is the vertical potential temperature gradient, $\frac{\partial u}{\partial z}$ is the vertical gradient of the zonal wind, and $\frac{\partial v}{\partial z}$ is the vertical gradient of the meridional wind. $R i$ is a measure of the dynamic instability and can 


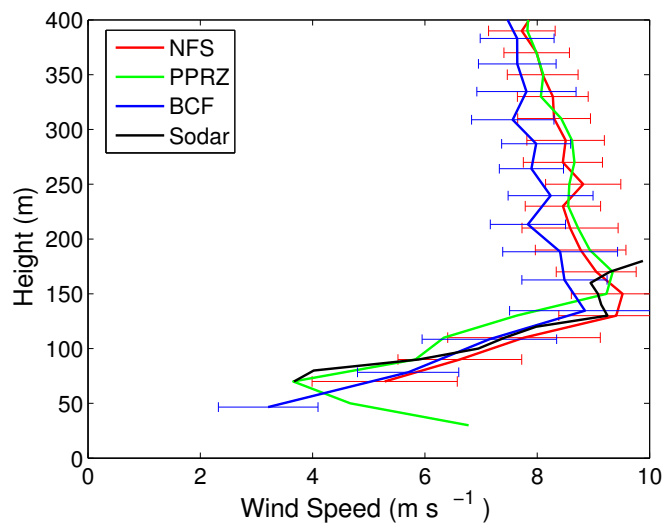

(a)

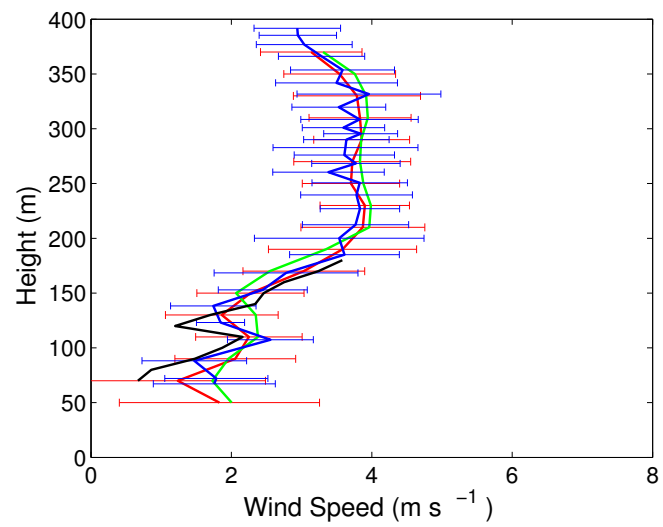

(c)

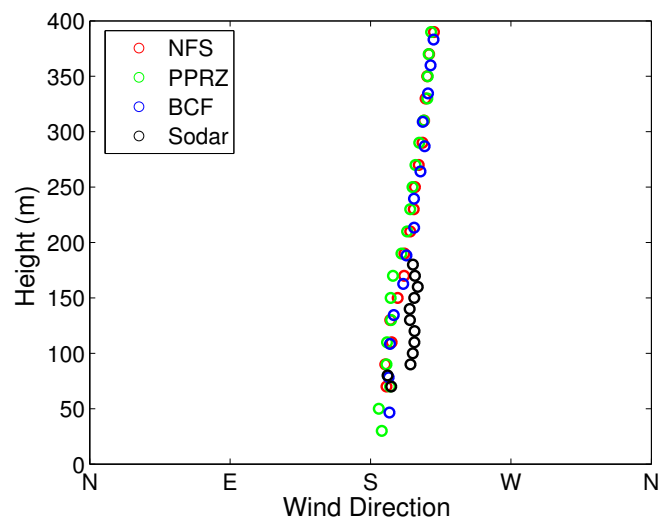

(b)

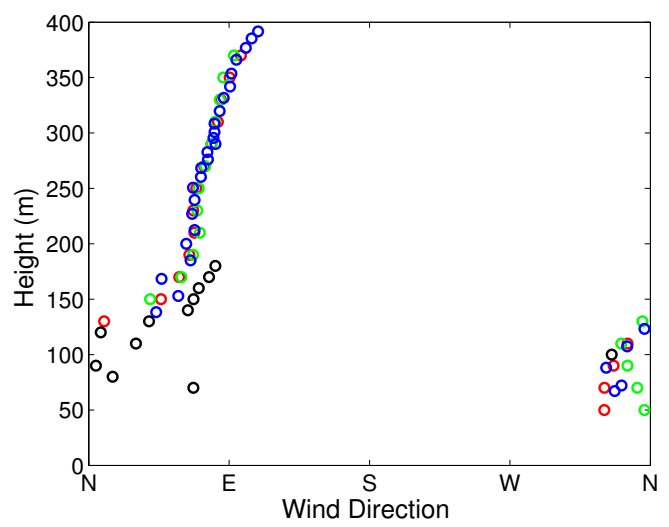

(d)

Fig. 6. Comparisons of wind profiles from a Scintec sodar (black) with derived wind speeds and directions from SMARTSonde flights. Algorithm acronyms in the legend are same as in Fig. 5. Data from (a) and (b) were taken on 31 October 2011 at 10:15 LT, while data from (c) and (d) were taken on 17 November 2011 at 08:36 LT.

be used to indicate the formation of turbulence. When $R i$ is less than a critical Richardson number, the flow is viewed as being dynamically unstable, allowing turbulence to develop or persist. If $R i$ is greater than the critical Richardson number, then the flow is dynamically stable and turbulence is expected to decay. In literature, the value of the critical Richardson number varies from $0.2-1$ or higher (Galperin et al., 2007), but the value is usually taken as 0.25 according to The Glossary of Meteorology of the American Meteorological Society.

Vertical profiles of $R i$ can be calculated through finite differencing of $\theta, u$, and $v$ with height. Although the SMARTSonde provides observations with high spatial resolution, the wind observations can be noisy with height. To reduce this effect on the calculation of the approximated gradient Richardson number, especially over short height intervals when $\Delta z$ becomes small (i.e., less than $10 \mathrm{~m}$ ), sets of three consecutive wind observations are averaged together, effectively creating one usable measurement for each set. After this averaging, $R i$ can be calculated between each measurement. Consequently the vertical resolution of $R i$ varies based on ascent rate, with lower resolution measurements when the aircraft is ascending quicker.

\subsection{Observations from 6 March 2011}

Four consecutive flights were conducted on the morning for 6 March 2011 to observe the early morning transition of the PBL. Sunrise (06:53 LT - local time) occurred approximately $30 \mathrm{~min}$ before the first flight. Thereafter, each flight took place approximately $30 \mathrm{~min}$ apart to allow the boundary layer to develop and change substantially between each profile. During the first two flights, the SMARTSonde ascended at a slow rate in order to sample the near-surface thermodynamic structure with high vertical resolution. The SMARTSonde ascended at a faster rate to penetrate the developing boundary layer during the last flights.

As the morning progressed, the depth of the convective boundary layer increased, as indicated by the increasing 


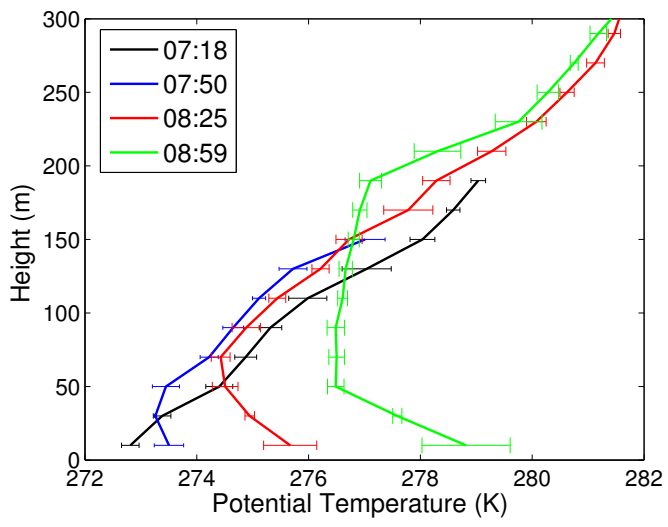

(a)
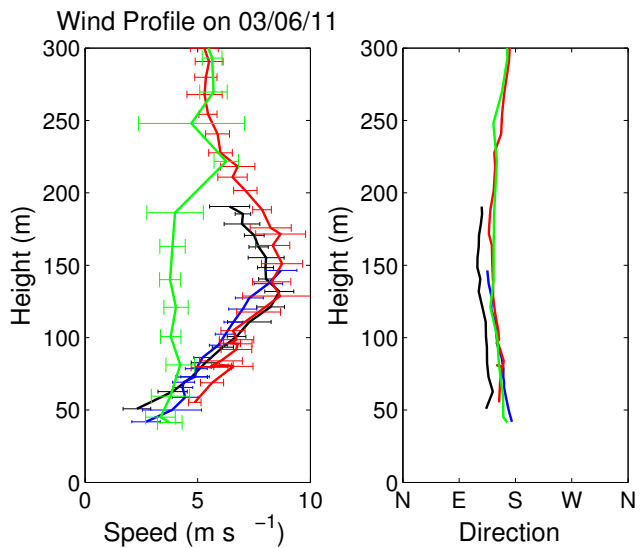

(c)

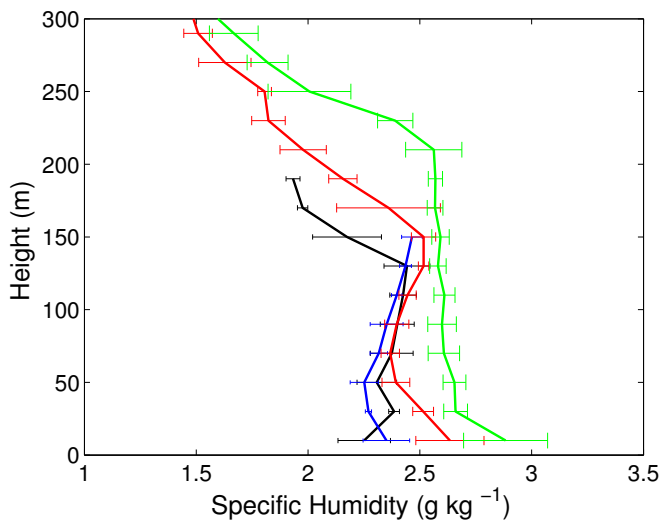

(b)

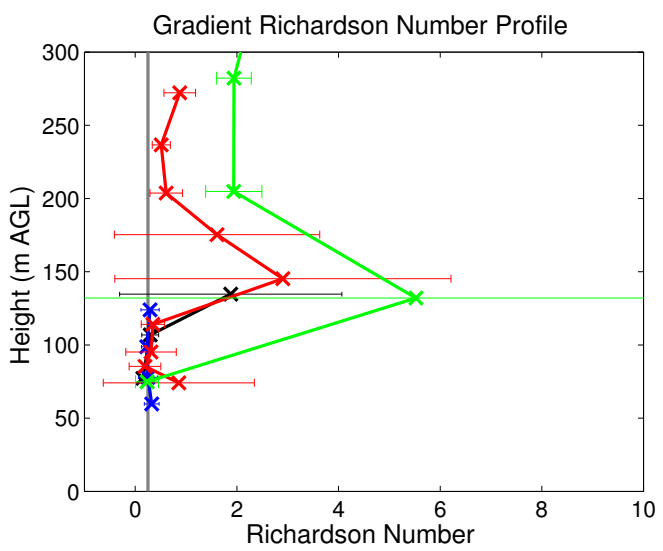

(d)

Fig. 7. SMARTSonde observations of the morning of 6 March 2011 from four sequential flights after sunrise. Provided is (a) potential temperature, (b) specific humidity, (c) wind profile using the BCF method, and (d) computed Richardson number. Local times for each flight is provided in the legend. Sunrise occurred at 06:53 LT.

height of the inversion shown in Fig. 7a. For the first $90 \mathrm{~min}$ after sunrise, the depth of the convective boundary layer increased at a slow pace, growing to be only slightly less than $100 \mathrm{~m}$ deep by 08:25 LT, as evidenced by the inversion. Afterwards, however, the rate of growth of the PBL drastically increased and reached a depth of about $200 \mathrm{~m}$ by 08:59 LT. This initial slow growth of the PBL followed by quick growth agrees well with past studies (White et al., 2002; Fisch et al., 2004). The depth of the PBL can be tracked by the moisture profiles in Fig. 7b, as the depth of the well-mixed moisture increases throughout the morning. In successive flights, the layer of air above the PBL in the entrainment zone cooled in time due to a negative heat flux as cool air from the surface is mixed upward and warmer air is mixed toward the surface, which agrees with results from Young et al. (2000) and Sullivan et al. (1998). Although it is difficult to draw definite conclusions from surface and upper air maps, there may be some weak cold, dry air advection occurring above the surface modifying the thermodynamic profile.
The wind profiles derived from the best-curve fitting method are shown in Fig. 7c. Wind profiles from the first three flights showed good agreement with each other. They each indicated a weak LLJ with a wind maximum of $\sim 8 \mathrm{~m} \mathrm{~s}^{-1}$ at $150 \mathrm{~m}$ a.g.l. with the wind speed decreasing above that height. By the last flight at 08:59 LT, the LLJ feature had disappeared. At this time, the wind speeds below $200 \mathrm{~m}$ a.g.l. had decreased to $\sim 4 \mathrm{~m} \mathrm{~s}^{-1}$ and were roughly constant with height above $50 \mathrm{~m}$ a.g.l. The decrease in wind speeds in this layer corresponds to the increase in the PBL depth during the same time interval between the third and fourth flights. Without a significant change in the synopticscale wind field, it can be assumed that the increase in the mixing depth is responsible for mixing down momentum from the LLJ. This is supported by the fact that the $10 \mathrm{~m}$ wind speed at the NWC Mesonet site increased by $\sim 2 \mathrm{~m} \mathrm{~s}^{-1}$ between 07:30-09:00 LT (not shown). If wind speeds were measured down to ground level with the SMARTSonde or another instrument, it would be possible to calculate the momentum fluxes using a modified integration approach from 
Deardorff et al. (1980) explained by Bonin et al. (2013) from consecutive wind profiles close in time.

By combining both the wind and thermodynamic profiles, profiles of $R i$ have been calculated and are shown in Fig. 7d. Assuming the errors associated with both potential temperature and wind are normally distributed, 10000 realizations of $R i$ were calculated using random values of $\theta, u$, and $v$ consistent with the mean and standard deviations for those values. The resulting mean value of $R i$ taken from the realizations is used as the reported value for the gradient Richardson number, while the error bars are based on the standard deviation of the 5-95\% confidence interval of the realizations. Realizations for which the wind shear is below $0.01 \mathrm{~s}^{-1}$ were removed. Otherwise, estimates of $R i$ would become unrealistically large. This is particularly noticeable during the last flight at $150 \mathrm{~m}$ where the wind shear is almost nonexistent. For this case, the denominator in Eq. (5), approaches zero and $R i$ becomes very large.

During the first three flights, $R i$ below $120 \mathrm{~m}$ a.g.l. was mostly determined to be at or below 0.25 . This value is primarily attributed to the strong shear associated with the bottom of the LLJ, before the momentum mixed downward. Despite the strong static stability, turbulence may be produced at these heights due to the strong shear. During all of the flights, there was an increase in $R i$ at $150 \mathrm{~m}$. This is likely due to the strong static stability and weak wind shear during the first three flights, and very weak wind shear with static stability during the fourth flight. This example shows the usefulness of having profiles of both thermodynamic and dynamic quantities of the PBL within $\sim 30$ min of each other.

\section{Conclusions}

Overall, the three algorithms that were tested with the SMARTSonde platform provided accurate results when compared with proximity rawinsonde and sodar observations. While the no-flow-sensor and BCF performed similarly, both seemed to provide more accurate estimates than the output from the Paparazzi autopilot software. Either algorithm could be used to measure the winds within $1.25 \mathrm{~m} \mathrm{~s}^{-1}$ and $16^{\circ}$ of rawinsonde observations. However, the fitting method provides the fastest independent observations when the aircraft is flying in small circles, which was the case for the flights provided in this study. The no-flow-sensor is the preferred algorithm to use when a limited number of turns are executed, since this algorithm does not require a change in heading for accurate retrievals.

These methods are used to accurately retrieve the 2-D wind vector from a low-cost UAS platform utilizing only data from an onboard GPS. Additional sensors, such as an IMU or probes with various dynamic and static pressure holes, could be incorporated onto the SMARTSonde or other UASs for faster and more accurate measurements. However, these sensors would significantly increase the cost of the platform.
It has been demonstrated that the wind estimates obtained can be combined with the thermodynamic profiles measured during the SMARTSonde flights to calculate the Richardson number with $50 \mathrm{~m}$ vertical resolution within the PBL. Additionally, the ability to make sequential wind and thermodynamic profiles with a vertical resolution of $\sim 10 \mathrm{~m}$ allows for closer examination of other interesting processes, such as the development of a LLJ in the evening or quantifying low-level wind shear in a pre-storm environment. UASs are unique platforms capable of taking high-resolution thermodynamic and dynamic measurements, and can be used to examine many atmospheric processes in a new way.

Acknowledgements. We thank our colleagues who have helped with the collection of the data, including all of those who have assisted in the development of the SMARTSonde. We are especially grateful to Wayne Shalamunec for piloting the SMARTSonde and putting many hours into the project, and to the Central Oklahoma Radio Control Society for allowing use of their airfield for flights. We would like to thank Alan Shapiro for his helpful comments. We are grateful for the anonymous reviewers' comments, which have improved the quality of this article. Funding to support the development of SMARTSonde has been provided by the University of Oklahoma (OU) Advanced Radar Research Center (ARRC) and through a grant provided by the National Oceanic Atmospheric Administration (NOAA) National Severe Storms Laboratory (NSSL).

Edited by: A. Benedetto

\section{References}

Barthelmie, R., Grisogono, B., and Pryon, S.: Observations and simulations of diurnal cycles of near-surface wind speeds over land and sea, J. Geophys. Res., 101, 21327-21337, 1996.

Bonin, T., Chilson, P. B., Zielke, B., and Fedorovich, E.: Observations of early evening boundary-layer transitions using a small unmanned aerial system, Bound.-Lay. Meteorol., 146, 119-132, 2013.

Bonner, W. D.: Climatology of the Low Level Jet, Mon. Weather Rev., 96, 833-850, 1968.

Brisset, P., Drouin, A., Gorraz, M., Huard, P.-S., and Tyler, J.: The Paparazzi solution, http://www.recherche.enac.fr/paparazzi/ papers_2006/mav06_paparazzi.pdf (last access: 18 December 2012), 2006.

Brock, F. V., Crawford, K. C., Elliott, R. L., Cuperus, G. W., Stadler, S. J., Johnson, H. L., and Eilts, M. D.: The Oklahoma Mesonet: A Technical Overview, J. Atmos. Ocean. Tech., 12, 5-19, 1995.

Chilson, P. B., Gleason, A., Zielke, B., Nai, F., Yeary, M., Klein, P. M., and Shalamunec, W.: SMARTSonde: A Small UAS platform to support radar research, in: 34th Conference on Radar Meteorology, Extended abstract 12B.6, available at: http://ams.confex.com/ams/34Radar/techprogram/paper_ 156396.htm, American Meteorological Society, Boston, Mass., 2009. 
Deardorff, J., Willis, G., and Stockton, B.: Laboratory Studies of the Entrainment Zone of a Convectively Mixed Layer, J. Fluid Mech., 100, 41-64, 1980.

Dias, N., Gonçalves, J., Freire, L., Hasegawa, T., and Malheiros, A.: Obtaining Potential Virtual Temperature Profiles, Entrainment Fluxes, and Spectra from Mini Unmanned Aerial Vehicle Data, Bound.-Lay. Meteorol., 145, 93-111, 2012.

Emeis, S., Harris, M., and Banta, R. M.: Boundary-layer anemometry by optical remote sensing for wind energy applications, Meteorol. Z., 16, 337-347, 2007.

Endlich, R., Ludwig, F., Bhumralkar, C., and Estoque, M.: A Diagnostic Model for Estimating Winds at Potential Sites for Wind Turbines, J. Appl. Meteorol., 21, 1441-1454, 1982.

Fisch, G., Tota, J., Machado, L., Silva Dias, M., da F. Lyra, R., Nobre, C., Dolman, A., and Gash, J.: The convective boundary layer over pasture and forest in Amazonia, Theor. Appl. Climatol., 78, 47-59, 2004.

Galperin, B., Sukoriansky, S., and Anderson, P. S.: On the critical Richardson number in stably stratified turbulence, Atmos. Sci. Lett., 8, 65-69, 2007.

Holland, G., Webster, P., Curry, J., Tyrell, G., Gauntlett, D., Brett, G., Becker, J., Hoag, R., and Vaglienti, W.: The Aerosonde Robotic Aircraft: A New Paradigm for Environmental Observations, B. Am. Meteorol. Soc., 82, 889-901, 2001.

Holton, J. R.: The Diurnal Boundary Layer Wind Oscillation Above Sloping Terrain, Tellus, 19, 199-205, 1967.

Houston, A., Argrow, B., Elston, J. S., Lahowetz, J., Frew, E., and Kennedy, P. C.: The Collaborative Colorado-Nebraska Unmanned Aircraft System Experiment, B. Am. Meteorol. Soc., 93, 39-54, 2012.

Kondragunta, S., Lee, P., McQueen, J., Kittaka, C., Prados, A., Ciren, P., Laszlo, I., Pierce, R., Hoff, R., and Szykman, J.: Air Quality Forecast Verification Using Satellite Data, J. Appl. Meteorol. Clim., 47, 425-442, 2008.

Lin, P.-H.: Observations: The First Successful Typhoon EyewallPenetration Reconnaissance Flight Mission Conducted by the Unmanned Aerial Vehicle, Aerosonde, B. Am. Meteorol. Soc., 87, 1481-1483, 2006.

Martin, S., Bange, J., and Beyrich, F.: Meteorological profiling of the lower troposphere using the research UAV " $\mathrm{M}^{2} \mathrm{AV}$ Carolo" Atmos. Meas. Tech., 4, 705-716, doi:10.5194/amt-4-705-2011, 2011.

Mayer, S., Hattenberger, G., Brisset, P., Jonassen, M., and Reuder, J.: A 'no-flow-sensor' Wind Estimation Algorithm for Unmanned Aerial Systems, Int. J. Micro Air Vehicl., 4, 15-29, 2012.

McPherson, R. A., Fiebrich, C. A., Crawford, K. C., Kilby, J. R., Grimsley, D. L., Martinez, J. E., Basara, J. B., Illston, B. G., Morris, D. A., Kloesel, K. A., Melvin, A. D., Shrivastava, H., Wolfinbarger, J. M., Bostic, J. P., Demko, D. B., Elliott, R. L., Stadler, S. J., Carlson, J., and Sutherland, A. J.: Statewide Monitoring of the Mesoscale Environment: A Techincal Update on the Oklahoma Mesonet, J. Atmos. Ocean. Tech., 24, 301-321, 2007.
Nelder, J. and Mead, R.: A simplex method for function minimization, Comput. J., 7, 308-313, 1965.

Parish, T. R. and Oolman, L. D.: On the Role of Sloping Terrain in the Forcing of the Great Plains Low-Level Jet, J. Atmos. Sci., 67, 2690-2699, 2010.

Premerlani, W. and Bizard, P.: Direction Cosine Matrix IMU: Theory, gentlenav.googlecode.com/files/DCMDraft2.pdf (last access: 18 December 2012), 2009.

Reuder, J., Brisset, P., Jonassen, M., Müller, M., and Mayer, S.: The Small Unmanned Meteorological Observer SUMO: A new tool for atmospheric boundary layer research, Meteorol. Z., 18, 141147, 2009.

Seaman, N. L. and Michelson, S. A.: Mesoscale Meteorological Structure of a High-Ozone Episode during the 1995 NARSTONortheast Study, J. Appl. Meteorol., 39, 384-398, 2000.

Shapiro, A. and Fedorovich, E.: Nocturnal Low-Level Jet over a Shallow Slope, Acta Geophys., 57, 950-980, 2009.

Shuqing, M., Hongbin, C., Gai, W., Yi, P., and Qiang, L.: A Miniature Robotic Plane Meteorological Sounding System, Adv. Atmos. Sci., 21, 890-896, 2004.

Spiess, T., Bange, J., Buschmann, M., and Vörsmann, P.: First application of the meteorological Mini-UAV ' $\mathrm{M}^{2} \mathrm{AV}$ ', Meteorol. Z., 16, 159-169, 2007.

Sullivan, P. P., Moeng, C.-H., Stevens, B., Lenschow, D. H., and Major, S. D.: Structure of the Entrainment Zone Capping the Convective Atmospheric Boundary Layer, J. Atmos. Sci., 55, 3042-3064, 1998.

van den Kroonenberg, A., Martin, T., Buschmann, M., Bange, J., and Vorsmann, P.: Measuring the Wind Vector Using the Autonomous Mini Aerial Vehicle $\mathrm{M}^{2} \mathrm{AV}$, J. Atmos. Ocean. Tech., 25, 1969-1982, 2008.

van den Kroonenberg, A., Martin, S., Beyrich, F., and Bange, J.: Spatially-Averaged Temperature Structure Parameter Over a Heterogeneous Surface Measured by an Unmanned Aerial Vehicle, Bound.-Lay. Meteorol., 142, 55-77, 2012.

Wexler, H.: A Boundary Layer Interpretation of the Low-Level Jet, Tellus, 13, 368-378, 1961.

White, A., Templeman, B., Angevine, W., Zamora, R., King, C., Russell, C., Banta, R., Brewer, W., and Olszyna, K.: Regional contrast in morning transitions observed during the 1999 Southern Oxidants Study Nashville/Middle Tennessee Intensive, J. Geophys. Res., 107, 4726-4737, 2002.

Williams, A. and Marcotte, D.: Wind Measurements on an maneuvering twin-engine turboprop aircraft accounting for flow distortion, J. Atmos. Ocean. Tech., 17, 795-810, 2000.

Young, G. S., Cameron, B. K., and Hebble, E. E.: Observations of the entrainment zone in a rapitly entraining boundary layer, J. Atmos. Sci., 57, 3145-3160, 2000. 